\title{
TBX2 overexpression promotes proliferation and invasion through epithelial-mesenchymal transition and ERK signaling pathway
}

\author{
XINGYU LIU $^{1 *}$, ZHIFENG MIAO $^{1 *}$, ZHENNING WANG $^{1}$, TINGTING ZHAO $^{2}$, \\ YINGYING XU ${ }^{2}$, YONGXI SONG ${ }^{1}$, JINYU HUANG ${ }^{1}$, JUNYAN ZHANG $^{1}$, \\ HAO XU ${ }^{1}$, JIANHUA WU ${ }^{1}$ and HUIMIAN XU ${ }^{1}$ \\ Departments of ${ }^{1}$ Surgical Oncology and ${ }^{2}$ Breast Surgery, The First Affiliated Hospital of China Medical University, \\ Shenyang, Liaoning 110001, P.R. China
}

Received February 6, 2017; Accepted June 13, 2018

DOI: $10.3892 /$ etm.2018.7028

\begin{abstract}
The present study aimed to clarify the clinical significance and biological effects of T-box (TBX)2 and its potential mechanism in gastric cancer $(\mathrm{GC})$. TBX2 protein expression levels in human GC tissues were investigated using immunohistochemistry, and it was demonstrated that TBX2 was overexpressed in 55.9\% (90/161) GC samples. TBX2 overexpression correlated with tumor invasion, advanced tumor node metastasis stage and presence of lymph node metastasis. In addition, TBX2 correlated with poor patient survival. To investigate the effect of TBX2 on biological behaviors, TBX2 plasmid transfection was performed in SGC-7901 cells and TBX2 small interfering RNA knockdown was carried out in BGC-823 cells. MTT and matrigel invasion assays demonstrated that TBX2 overexpression promoted proliferation and invasion, whereas TBX2 depletion inhibited proliferation and invasion. TBX2 overexpression also promoted epithelial-mesenchymal transition by downregulating E-cadherin and upregulating $\mathrm{N}$-cadherin. TBX2 overexpression also upregulated matrix metalloproteinase (MMP)2, MMP9, cyclin $\mathrm{E}$ and phosphorylated-extracellular signal regulated kinase levels, however downregulated p21. In conclusion, TBX2 may serve as an effective predictor and therapeutic target in human GC.
\end{abstract}

Correspondence to: Professor Huimian Xu, Department of Surgical Oncology, The First Affiliated Hospital of China Medical University, 155 Nanjing Street, Shenyang, Liaoning 110001, P.R. China E-mail: xuhuimpaper@163.com

${ }^{*}$ Contributed equally

Key words: TBX2, gastric cancer, proliferation, invasion, EMT, ERK

\section{Introduction}

Gastric cancer (GC) is one of the most common malignant cancers in the world. The incidence of GC has declined with identification of several risk factors including dietary and environmental risks in the past several years (1-4). However, most patients diagnosed with GC at advanced stage have a low 5-year survival rate $(5,6)$. The main reason for the poor prognosis in GC is invasion and metastasis (7-9). To improve the understanding of GC progression, novel oncogenes and therapeutic targets should be explored.

T-box (TBX)2 is a member of T-box gene family which is one of the most prominent gene families in the field of embryonic development (10). Members in T-box gene family are highly conserved in evolution ranging from hydra to human (11-13). T-box transcription factors are characterized by a highly conserved DNA binding domain and have been shown to function as either transcriptional activators or repressors (14-17).

Genetic researches showed that T-box proteins are generally expressed in certain cell types of specific organs in flies, worms, fish, mice, dogs, and humans and they were reported to be necessary for the development of these structures $(18,19)$. In addition, a growing list of studies have reported dysregulation of T-box factors in different cancers and inappropriate T-box factor expression was directly linked to oncogenesis (20-23).

TBX2 overexpression was first reported in breast cancer tissues and cell lines, and high TBX2 level correlated with poor prognosis (24). TBX2 overexpression was also found in pancreatic cancer, endometrial cancer, colorectal cancer and cervical cancer (25-29). However, the effects of TBX2 on GC progression remains unclear. This study aims to clarify not only the clinical of TBX2 in GC tissues but also its biological functions and potential mechanisms.

\section{Materials and methods}

Patients and specimens. This study protocol was approved by the ethics review board of the First Affiliated Hospital of China Medical University (Shenyang, China). Primary tumor specimens were obtained from 161 patients diagnosed with GC who underwent resection in the First Affiliated Hospital 
of China Medical University between 2010 and 2015. The histological diagnosis was evaluated for sections stained with hematoxylin and eosin according to the 2004 World Health Organization (WHO) classification guidelines.

Immunohistochemistry. Immunohistochemistry was performed using the Elivision plus kit purchased from MaiXin (Fuzhou, China). Samples were prepared for $4-\mu \mathrm{m}$ thick tissue sections and deparaffinized using xylene. Sections were rehydrated with graded alcohol $(100 \%, 5 \mathrm{~min}$ for 2 times; 95\%, $2 \mathrm{~min}$; 80\%, $2 \mathrm{~min}$; 70\%, $2 \mathrm{~min})$. Citrate buffer ( $\mathrm{pH} 6.0 ; 2 \mathrm{~min})$ was used for antigen retrieval. $\mathrm{H}_{2} \mathrm{O}_{2}$ was used to block the endogenous peroxidase. Normal goat serum was used to reduce nonspecific binding. Sections were incubated with TBX2 antibody (rabbit polyclonal; dilution, 1:60; SAB2102383; Sigma-Aldrich; Merck KGaA, Darmstadt, Germany) overnight at $4^{\circ} \mathrm{C}$. A biotinylated anti-rabbit horseradish peroxidase polymer was used as a secondary antibody. The peroxidase reaction was developed with DAB plus from MaiXin. Counterstaining was done with hematoxylin, and the sections were dehydrated in alcohol before mounting.

Two independent investigators, who were blinded to the patient characteristics, examined all tumor slides randomly. To evaluate the staining, 400 tumor cells were counted and the intensity/percentage was calculated. The intensity of TBX2 staining was scored as 0 (no signal), 1 (moderate) or 2 (strong). Percentage scores were assigned as 1 (1-25\%), 2 (26-50\%), 3 $(51-75 \%)$ or $4(76-100 \%)$. The scores of each tumor sample were multiplied to give a final score of 0-8; tumor samples that scored 4-8 were considered as TBX2 overexpression.

Cell culture. BGC-823 and SGC-7901 cells were purchased from Shanghai Cell Bank (Shanghai, China). Cells were cultivated in DMEM (Invitrogen; Thermo Fisher Scientific, Inc., Waltham, MA, USA) supplemented with 10\% FBS (Invitrogen; Thermo Fisher Scientific, Inc.), with the conditions of $37^{\circ} \mathrm{C}$ and $5 \% \mathrm{CO}_{2}$. Cells were seeded at a density of $1 \times 10^{6}$ cells $/ \mathrm{ml}$. Cells were treated with paclitaxel (final concentration, $5 \mu \mathrm{M}$ ) after cells attached to the bottom for $24 \mathrm{~h}$.

Cell transfection. pCMV6 TBX2 plasmid was purchased from OriGene Technologies, Inc. (Rockville, MD, USA). Transfection was performed in SGC-7901 cell line using Attractene reagent (Qiagen GmbH, Hilden, Germany). siGENOME TBX2 siRNAs pool and Negative siRNAs pool were purchased from GE Healthcare Dharmacon, Inc. (Lafayette, CO, USA). siRNA was transfected into BGC-823 cell line with DharmaFECT1 (GE Healthcare Dharmacon, Inc.).

Western blotting. Total protein of cells was extracted using lysis buffer (Pierce; Thermo Fisher Scientific, Inc.) and quantified by Bradford method. $30 \mu \mathrm{g}$ protein was separated by SDS-PAGE. Samples were transferred to polyvinylidene fluoride membranes (EMD Millipore, Billerica, MA, USA) and incubated overnight at $4^{\circ} \mathrm{C}$ with antibody against cyclin E (20808; Cell Signaling Technology, Inc., Danvers, MA, USA), matrix metalloproteinase (MMP)2 (1:1,000; cat. no. 4022; Cell Signaling Technology, Inc.), MMP9 (1:1,000; cat. no. 3852; Cell Signaling Technology, Inc.), E-cadherin (24E10) $(1: 1,000$; cat. no. 3195; Cell Signaling
Technology, Inc.), N-cadherin (1:600; cat. no. 13116; Cell Signaling Technology, Inc.), p21 (Waf1/Cip1;12D1) (1:1,000; cat. no. 2947; Cell Signaling Technology, Inc.), p-ERK (1:1,000; cat. no. 9101; Cell Signaling Technology, Inc.), ERK (1:1,000; cat. no. 4695; Cell Signaling Technology, Inc.), $\beta$-actin (1:3,000; cat. no. 4967; Cell Signaling Technology, Inc.), GAPDH (1:3,000; cat. no. G5262; Santa Cruz Biotechnology, Inc., Dallas, TX, USA). After incubation with peroxidase-coupled anti-mouse/rabbit IgG $(1: 1,000$; Cell Signaling Technology, Inc.) at $37^{\circ} \mathrm{C}$ for $2 \mathrm{~h}$, bound proteins were visualized using ECL (Pierce; Thermo Fisher Scientific, Inc.) and detected using a DNR BioImaging System (DNR, Jerusalem, Israel). Relative protein levels were quantified using ImageJ software.

Reverse transcription-quantitative polymerase chain reaction (RT-qPCR). Total RNA was extracted using TRIzol Reagent (Thermo Fisher Scientific, Inc.). Total RNA was reverse transcribed using PrimeScript RT Master Mix (5X). A total of $10 \mu \mathrm{l}$ of reverse transcribed reaction system was consisted of $800 \mathrm{ng}$ RNA template, $2 \mu \mathrm{l}$ RT master mix and moderate volume of RNase-free $\mathrm{H}_{2} \mathrm{O}$. Real-time PCR was performed using SYBR-Green master mix kit (ABI, USA) with a 7500 Real-Time PCR System (Applied Biosystems; Thermo Fisher Scientific, Inc.). PCR reaction system was consisted of $10 \mu \mathrm{l}$ SYBR-Green master mix, $4 \mu 1$ RNase-free $\mathrm{H}_{2} \mathrm{O}, 0.5 \mu 1$ forward primer, $0.5 \mu 1$ reverse primer and $5 \mu 1 \mathrm{cDNA}$ template. The process of PCR was $95^{\circ} \mathrm{C}$ for $2 \mathrm{~min}, 40$ cycles of $95^{\circ} \mathrm{C}$ for $2 \mathrm{sec}$, annealing/extension at $60^{\circ} \mathrm{C}$ for $30 \mathrm{sec}$. A dissociation step was performed to generate melting curves to confirm the specificity of the amplification. Expression levels of the analyzed genes were normalized to the expression of $\beta$-actin. The fold change of gene expression was calculated by the $2^{-\Delta \Delta \mathrm{Cq}}$ method. The sequences of the primer pairs are as follows: TBX2 forward, 5'-GGCTTCAACATCCTAAACTCC-3'; and reverse, 5'-AAG ATCGACCAACAACCCGTTT-3'. $\beta$-actin forward, 5 '-ATA GCACAGCCTGGATAGCAACGTAC-3'; and reverse, 5'-CAC CTTCTACAATGAGCTGCGTGTG-3'.

MTT assay. Cells $\left(5 \times 10^{3} /\right.$ well) were plated in $96-$ well plates and then cultured overnight. $20 \mu \mathrm{l}$ of $5 \mathrm{mg} / \mathrm{ml}$ MTT [3-(4,5-dimethylthiazol-2-yl)-2,5-diphenyltetrazolium bromide; Sigma-Aldrich; Merck KGaA] solution was added to each well and incubated for another $4 \mathrm{~h}$ at $37^{\circ} \mathrm{C}$. The supernatant was removed and DMSO $(150 \mu \mathrm{l})$ was added to dissolve the formazan crystals. Absorbance was measured at $490 \mathrm{~nm}$. Data was obtained from triplicate wells per condition and representative of at least three independent experiments.

Matrigel invasion assay. Matrigel invasion assay was performed using a 24-well Transwell chamber. $48 \mathrm{~h}$ after the transfection, cells were trypsinized and inoculated to the upper chamber with our serum and incubated for $18 \mathrm{~h}$. Lower chamber was added with medium supplemented with $10 \%$ serum. Non-invaded cells were wiped out and cells invaded through the filter were fixed with $4 \%$ paraformaldehyde and stained with hematoxylin. The number of invading cells was counted under electron microscope (Olympus BX53; Olympus Corporation, Tokyo, Japan). 
Table I. Distribution of TBX2 status in gastric cancer according to clinicopathological characteristics.

\begin{tabular}{|c|c|c|c|c|}
\hline Characteristics & Number of patients & TBX2 low expression & TBX2 high expression & P-value \\
\hline Age & & & & 0.7901 \\
\hline$<60$ & 82 & 37 & 45 & \\
\hline$\geq 60$ & 79 & 34 & 45 & \\
\hline Sex & & & & 0.2644 \\
\hline Male & 116 & 48 & 68 & \\
\hline Female & 45 & 23 & 22 & \\
\hline Differentiation & & & & 0.6369 \\
\hline Poor & 76 & 35 & 41 & \\
\hline Well-moderate & 85 & 36 & 49 & \\
\hline Tumor invasion $(\mathrm{T})$ & & & & 0.0460 \\
\hline $\mathrm{T} 1+\mathrm{T} 2$ & 61 & 33 & 28 & \\
\hline $\mathrm{T} 3+\mathrm{T} 4$ & 100 & 38 & 62 & \\
\hline Lymph node metastasis & & & & 0.0051 \\
\hline Absent & 60 & 35 & 25 & \\
\hline Present & 101 & 36 & 65 & \\
\hline TNM stage & & & & $<0.0001$ \\
\hline $\mathrm{I}+\mathrm{II}$ & 76 & 48 & 28 & \\
\hline III & 85 & 23 & 62 & \\
\hline
\end{tabular}

TBX2, T-box 2; TNM, tumour node metastasis.
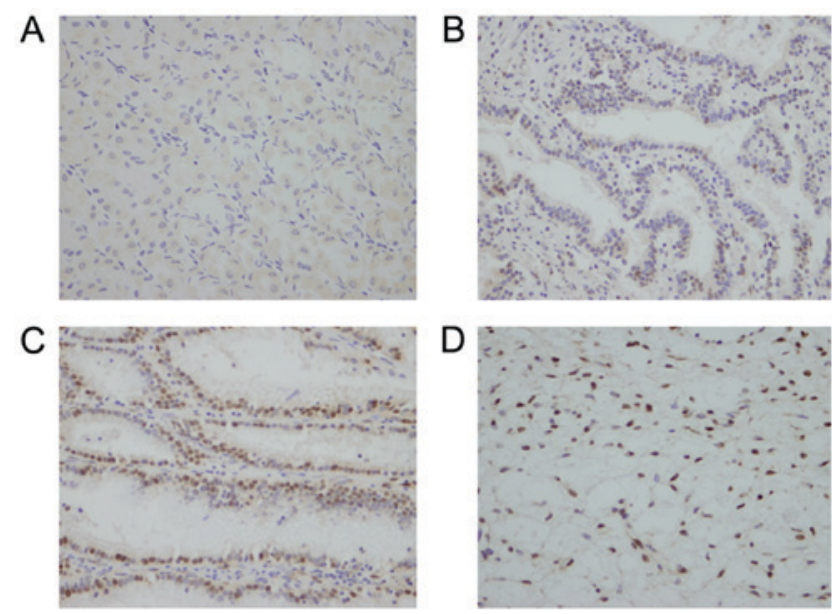

Figure 1. Expression pattern on T-box 2 (TBX2) in human gastric cancer. (A). Negative staining of TBX2 protein in non-cancerous gastric tissue.(B) Negative staining of TBX2 protein in gastric cancer tissue with well-moderate differentiation. (C) Nuclear positive staining of TBX2 protein in gastric cancer tissue with well-moderate differentiation. (D) Cytoplasm positive staining of TBX2 protein in gastric cancer tissue with poor differentiation.

Statistical analysis. SPSS version 16 for Windows (SPSS, Inc., Chicago, IL, USA) was used for all statistical analyses. A $\chi^{2}$ test was used to examine possible associations between TBX2 expression and clinicopathological factors. The Kaplan-Meier method was used to estimate the probability of patient survival, and differences in the survival of subgroups of patients were compared by using Mantel's log-rank test. Cox proportional hazards regressions were applied to estimate the individual hazard ratio (HR). The Student's t-test was used to compare differences between control and treatment groups. $\mathrm{P}<0.05$ was considered to indicate a statistically significant difference.

\section{Results}

TBX2 is overexpressed in human GC. To explore expression pattern of TBX2 in human GC, 161 cases of GC tissues and 10 cases of normal gastric tissues were collected and then TBX2 protein expression was determined using immunohistochemistry. As shown in Fig. 1A, negative staining was observed in normal gastric tissue. Positive nuclear staining was observed in 90 of 161 (55.9\%) cases of GCs (Fig. 1B-D). The relationship between TBX2 expression and various clinicopathological parameters was analyzed and the results were listed in Table I. It was observed that TBX2 overexpression was significantly associated with deep tumor invasion (T1+T2 $45.9 \%$ vs. T3+T4 62\%; P=0.0460), advanced TNM stage (I+II $36.8 \%$ vs. III $72.9 \%$; $\mathrm{P}<0.0001)$ and presence of nodal metastasis (absent $41.7 \%$ vs. present $64.4 \%$; $\mathrm{P}=0.0051$ ). To investigate the association between TBX2 expression and prognosis, Kaplan-Meier analysis was performed and the results showed that patients with higher TBX2 levels showed poorer survival than those with low TBX2 levels ( $\mathrm{P}<0.05$; Fig. 2). In addition, Cox regression analysis revealed that $\mathrm{TBX} 2$ was predictor for overall survival of patients with GCs using univariate analysis (Table II).

Expression pattern of TBX2 in GC cells. TBX2 protein expression in normal and cancerous gastric cells (GES-1, BGC-823, AGS, SGC-7901, MKN-1 and HGC-27) was detected by 
Table II. Multivariate analysis for predictive factors in patients with gastric cancer (Cox regression model).

\begin{tabular}{|c|c|c|c|c|}
\hline \multirow[b]{2}{*}{ Factors } & \multicolumn{2}{|l|}{ Univariate } & \multicolumn{2}{|c|}{ Multivariate } \\
\hline & Hazard ratio $(95 \% \mathrm{CI})$ & P-value & Hazard ratio $(95 \% \mathrm{CI})$ & P-value \\
\hline TBX2 overexpression & $2.027(1.284-3.201)$ & 0.0024 & $1.049(0.636-1.730)$ & 0.8524 \\
\hline Stage & $2.127(1.560-2.906)$ & $<0.0001$ & $2.285(1.553-3.363)$ & $<0.0001$ \\
\hline Differentiation & $1.103(0.716-1.697)$ & 0.6567 & $0.874(0.560-1.363)$ & 0.5519 \\
\hline Relapse & $70.552(21.978-226.486)$ & 90 & $83.884(26.938-306.633)$ & $<0.0001$ \\
\hline
\end{tabular}

CI, confidence interval; TBX, T-box.

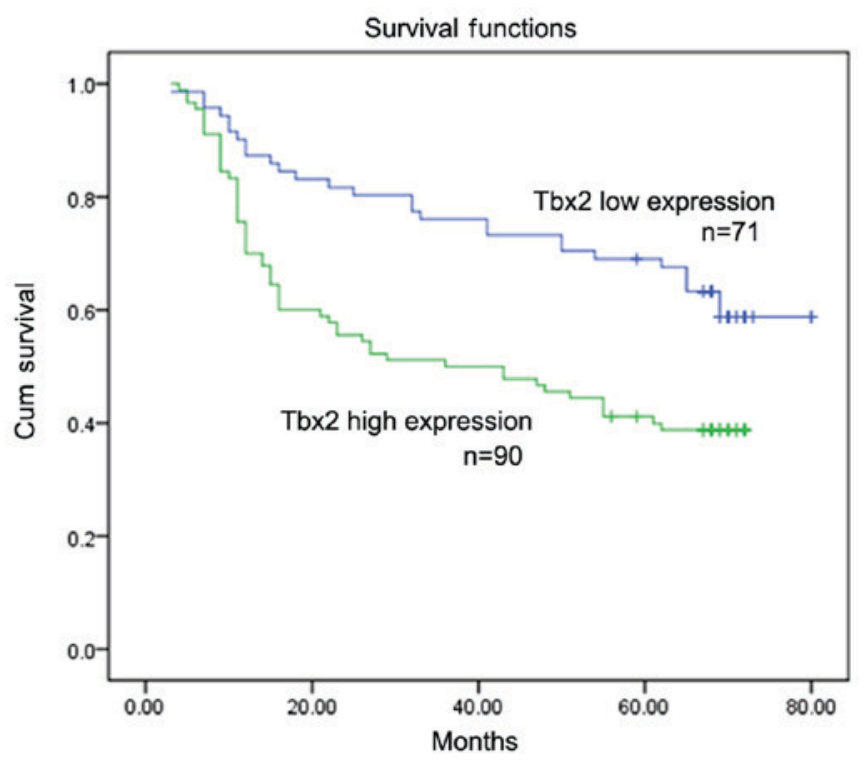

Figure 2. Correlation between T-box 2 (TBX2) expression and prognosis. Kaplan-Meier analysis results demonstrated that patients with high TBX2 levels showed poor survival and patients with low TBX2 levels showed good prognosis $(\mathrm{P}=0.0017)$.

western blot. As shown in Fig. 3A, relative high level of TBX2 was found in BGC-823 cells while low TBX2 expression was found in SGC-7901 cells. In order to confirm effect of TBX2 on GC cells, we adopted SGC-7901 and BGC-823 to perform TBX2 transfection and siRNA interference. Western blot results showed that TBX2 protein expression was significantly upregulated in SGC-7901 cells when transfected with TBX2 plasmid while downregulated in BGC-823 cells when treated with TBX2 siRNA (Fig. 3B). Quantitative PCR showed similar results.

TBX2 promotes cell proliferation and invasion in GC cells. MTT assay was employed to measure the effect of TBX2 on cell viability. TBX2 overexpression induced cell growth rate significantly while TBX2 depletion decreased cell growth rate (Fig. 4A). Matrigel invasion assay was performed to explore change of cell invasion. It was observed that number of invading cells increased significantly after TBX2 overexpression while decreased after TBX2 depletion (Fig. 4B). These results demonstrated that TBX2 enhanced the ability of proliferation and invasion in GC cells.
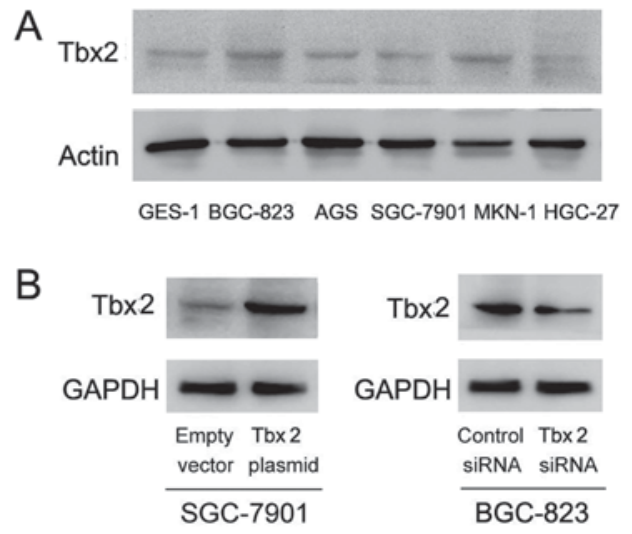

C
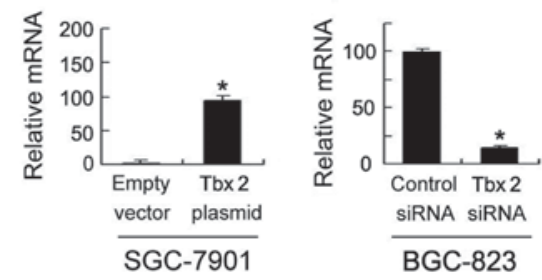

Figure 3. Expression pattern of T-box 2 (TBX2) in gastric cancer cell lines and the transfection efficiency. (A) Western blot analysis was employed to detect expression of TBX2 in gastric cancer cell lines included GES-1, BGC-823, AGS, SGC-7901, MKN-1, HGC-27. The results showed that TBX2 protein expression was relatively high in BGC-823 cells and low in SGC-7901 cells. (B) TBX2 plasmid and siRNA were transfected into SGC-7901 and BGC-823 cells respectively, and then transfection efficiency was evaluated using western blot. TBX2 expression was upregulated when transfected with TBX2 plasmid and downregulated when transfected with TBX2 siRNA. (C) Transfection efficiency was evaluated using qPCR. The results showed that TBX2 mRNA level was increased when transfected with TBX2 plasmid $(\mathrm{P}<0.05)$ and decreased when transfected with TBX2 siRNA $(\mathrm{P}<0.05)$. ${ }^{*} \mathrm{P}<0.05$.

TBX2 promotes EMT and ERK signaling pathway. To investigate the potential mechanism responsible for the effect of TBX2 on cell biological behaviors, related factors were detected using western blot. As shown in Fig. 5, levels of MMP2, MMP9, cyclin E, N-cadherin were increased while E-cadherin and p21 levels decreased in SGC-7901 cells transfected with TBX2 plasmid. In BGC-823 cells, TBX2 depletion enhanced expression of E-cadherin and p21 while suppressed expression of MMP2, MMP9, N-cadherin and cyclin E.

To further explore the possible molecular mechanism, MAPKs signaling pathway was examined using western blot. ERK phosphorylation level was increased in SGC-7901 cells 
A

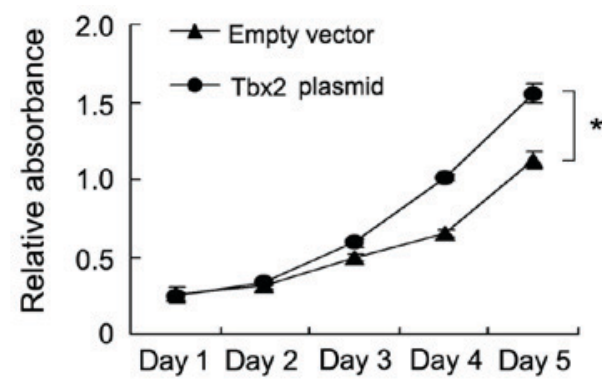

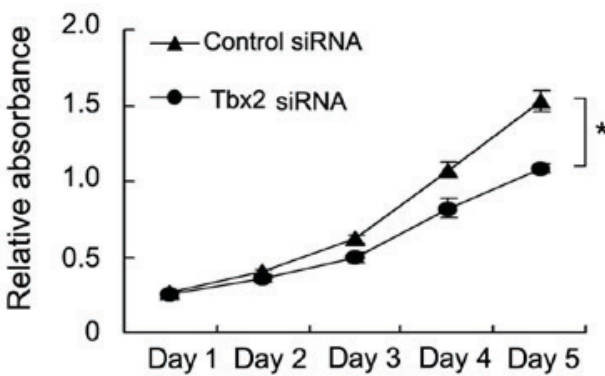
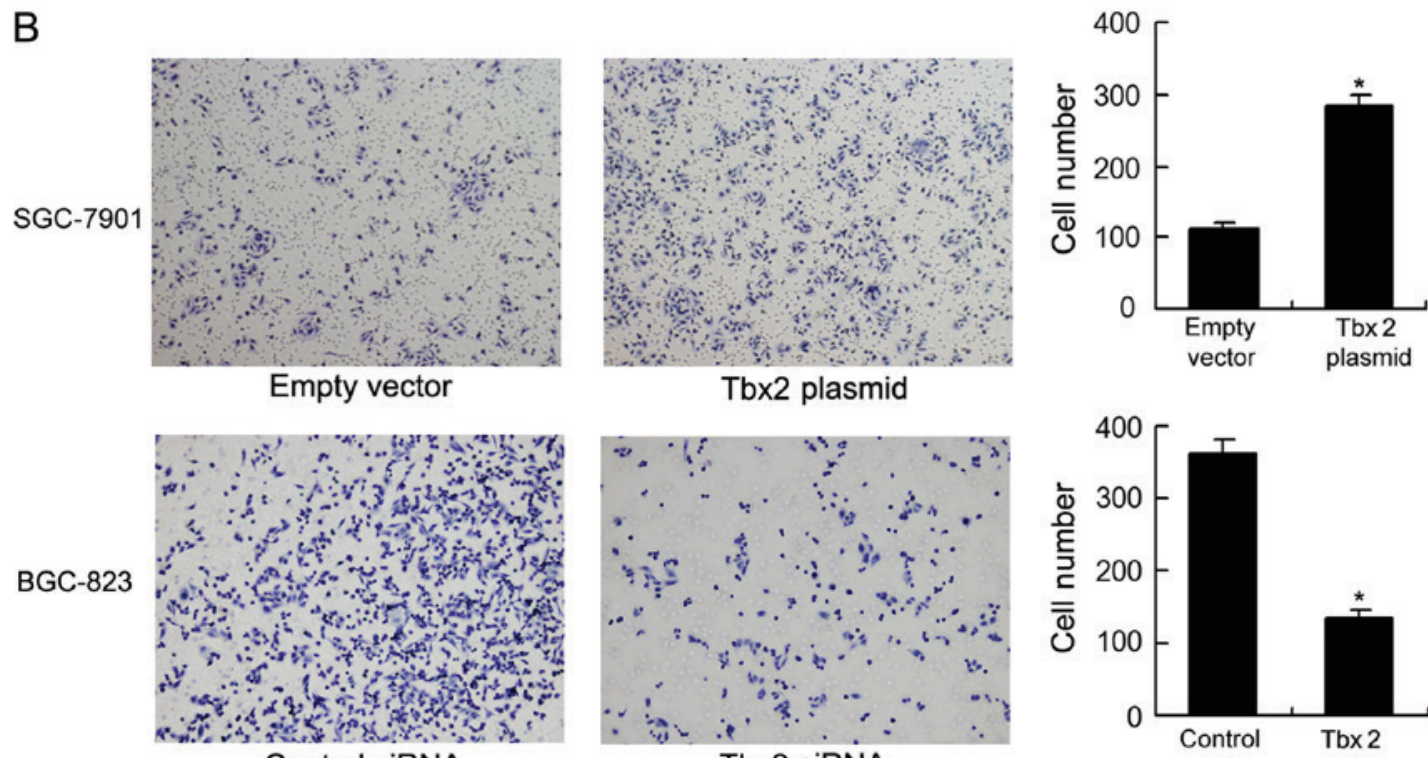

Control siRNA
Tbx2 plasmid
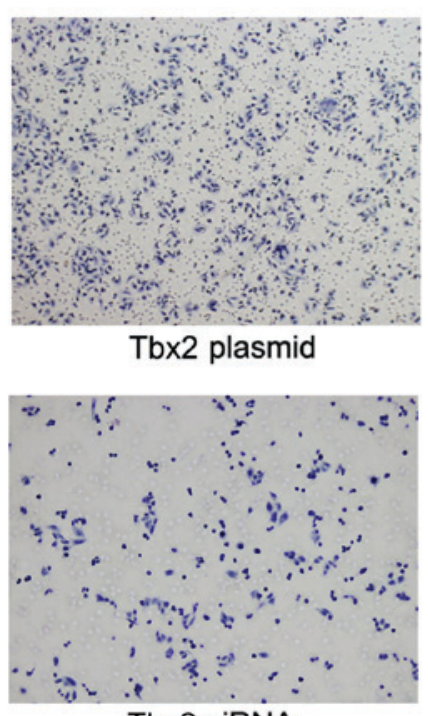

Tbx2 siRNA

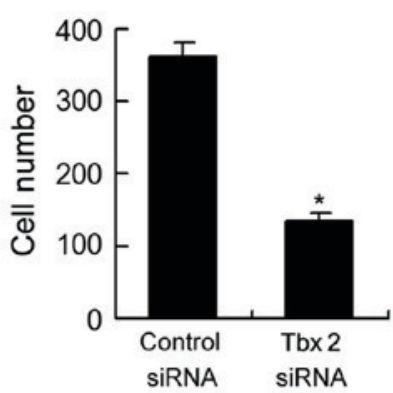

Figure 4. T-box 2 (TBX2) promote proliferation and invasion in gastric cancer cells. (A) MTT assay was employed to analyze change of growth rate in gastric cancer cells under the effect of TBX2. The results showed that growth rate in SGC-7901 cells treated with TBX2 plasmid was increased compared with cells treated with empty vector. Growth rate was decreased in BGC-823 cells treated with TBX2 siRNA compared with control siRNA. (B) Effect of TBX2 on cell invasion was examined using matrigel invasion assay. The results showed that number of invading cells was increased significantly when transfected with TBX2 plasmid $(\mathrm{P}<0.05)$ and decreased significantly when transfected with TBX2 siRNA $(\mathrm{P}<0.05)$. ${ }^{*} \mathrm{P}<0.05$.

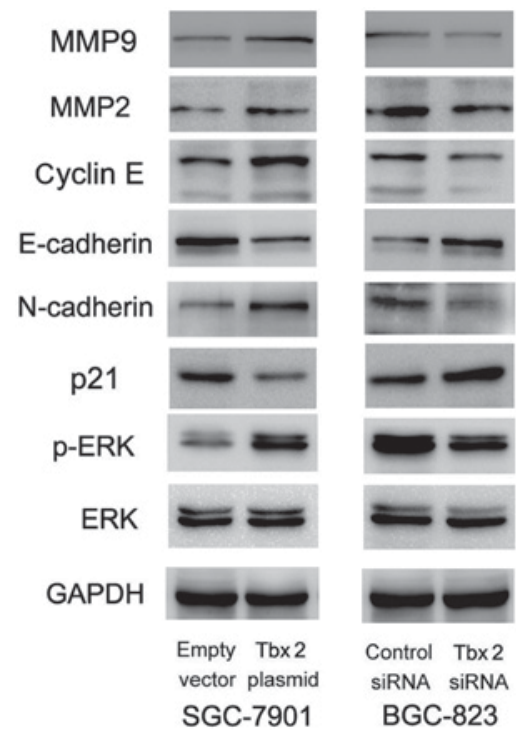

Figure 5. T-box 2 (TBX2) regulates expression of matrix metalloproteinase (MMP)2, MMP9, cyclin E, E-cadherin, p21 and p-ERK. Expression of MMP2, MMP9, cyclin E and p-ERK was upregulated after TBX2 overexpression in SGC-7901 cells while downregulated after TBX2 depletion in BGC-823 cells. E-cadherin and p21 levels were decreased after TBX2 overexpression in SGC-7901 cells while increased after TBX2 depletion in BGC-823 cells. Western blotting was repeated in triplicate and representative result was shown. transfected with TBX2 plasmid and decreased in BGC-823 cells transfected with TBX2 siRNA.

\section{Discussion}

In the present study, we examined TBX2 expression pattern in GC tissues. The results revealed that TBX2 was upregulated in GC tissues, with significant association with local invasion, advanced TNM stage and presence of nodal metastasis. These results suggested TBX2 correlated with malignant phenotype of GCs. We also observed that patients with high TBX2 showed worse prognosis compared with those with low TBX2 expression, suggesting that TBX2 is a potential diagnostic or prognostic cancer marker.

We also found that TBX2 directly regulated the progression of GC cells. Transfection or knocking down of TBX2 was sufficient to change the ability of cell proliferation, invasion. Previous studies reported that TBX2 functioned as a potent growth-promoter in malignant tumors partly due to its ability to bypass senescence and repress key negative regulators of the cell cycle $(30,31)$. We observed that cell proliferation rate was increased after TBX2 overexpression while decreased after TBX2 depletion. Matrigel invasion results showed that invading cells was increased transfected 
with TBX2 plasmid while decreased when transfected with TBX2 siRNA, suggesting that TBX2 promoted the ability of invasion.

To clarify the potential mechanism responsible for the regulatory effect of TBX2 on cell biological behaviors in GC cells, we examined expression of related protein including MMPs, cyclins and p21. It was observed that expression of MMP2, MMP9 and cyclin E was increased after TBX2 overexpression while decreased when TBX2 depletion. MMPs are calcium-dependent zinc-containing endopeptidases, which are capable of degrading all kinds of extracellular matrix proteins and processing a number of bioactive molecules (32-34). Tumor invasion is a phenomenon that requires increased motility and proteolysis and MMPs have been suggested to be critical for the invasive and metastatic potential in varieties of malignant tumors (35-37). In addition, we observed that TBX2 reduced the expression of epithelial-mesenchymal transition marker E-cadherin while upregulated $\mathrm{N}$-cadherin. Epithelial-to-mesenchymal transition (EMT) activation is a process that involves the transcriptional repression of epithelial markers such as E-cadherin, which is pivotal during cancer invasion and metastasis $(38,39)$. Thus TBX2 promote cell invasion partly through regulating MMP2, MMP9 and E-cadherin levels.

TBX2 has been confirmed to function as transcriptional repressors and promote the bypass of senescence by downregulating expression of the negative cell cycle regulators $\mathrm{p} 21$ (40). Another reports showed that TBX2 protein is a direct repressor of the $\mathrm{p} 21$ promoter through an element located close to the p21 transcription start site $(40,41)$. Our study was consistent with previous conclusions, showing that TBX2 overexpression downregulated p21 level in SGC-7901 cells while TBX2 depletion upregulated p21 level in BGC-823 cells. We also found that TBX2 positively regulated cyclin E expression. Cyclin E normally accumulates at the G1/S phase transition and then accelerates the speed of cell proliferation $(42,43)$. According to above findings, we speculated that TBX2 affected cell proliferation partly through regulating p21 and cyclin E expression in GC cells. TBX2 was reported to represses Connexin43, which functions as gap junction protein (44). TBX2 could also represses CST6, which induced sustained breast cancer proliferation (45). It is also reported that TBX2 promoting transcription of the canonical WNT3A promoter (46). Thus TBX2 is a multifunctional gene regulator which could either inhibit or activate transcription.

To further investigate potential molecule mechanism, MAPK signaling pathway was examined. Level of p-ERK increased in SGC-7901 cells transfected with TBX2, while p-ERK level decreased in BGC-823 cells interferenced with TBX2 siRNA. The ERK cascade functions in cellular proliferation, differentiation, and survival, and its activation promotes tumor progression (47-50). We speculated that regulatory effect of TBX2 in GC may partly depend on ERK signaling pathway.

In conclusion, TBX2 is upregulated in GCs and correlates with lymph node metastasis, local invasion, TNM stage and poor prognosis. TBX2 promotes proliferation, invasion through regulation of MMP2, MMP9, cyclin E, E-cadherin and p21 through ERK signaling pathway. TBX2 might serve as an effective biomarker and therapeutic target in human GCs.

\section{References}

1. Castro C, Peleteiro B, Bento MJ and Lunet N: Trends in gastric and esophageal cancer incidence in northern Portugal (1994-2009) by subsite and histology and predictions for 2015. Tumori 103: 155-163, 2017.

2. Leylabadlo HE, Kafil HS and Yousefi M: Gastric cancer mortality in a high-incidence area (Ardabil Province, Northwest Iran): What risk factors are causative? Eur J Cancer Prev 25: 573-574, 2016.

3. Yoon SB, Park JM, Lim CH, Kim JS, Cho YK, Lee BI, Lee IS, Kim SW and Choi MG: Incidence of gastric cancer after endoscopic resection of gastric adenoma. Gastrointest Endosc 83: 1176-1183, 2016.

4. Nicolas C, Sylvain M, Come L, Jean F, Anne-Marie B and Valerie J: Trends in gastric cancer incidence: A period and birth cohort analysis in a well-defined French population. Gastric Cancer 19: 508-514, 2016.

5. Wu H, Cai Z, Lu G, Cao S, Huang H, Jiang Y and Sun W: Impact of c-erbB-2 protein on 5-year survival rate of gastric cancer patients after surgery: A cohort study and meta-analysis. Tumori 103: 249-254, 2017.

6. Greenhill C: Gastric cancer. Metformin improves survival and recurrence rate in patients with diabetes and gastric cancer. Nat Rev Gastroenterol Hepatol 12: 124, 2015.

7. Xie R, Wang X, Qi G, Wu Z, Wei R, Li P and Zhang D: DDR1 enhances invasion and metastasis of gastric cancer via epithelial-mesenchymal transition. Tumour Biol 37: 12049-12059, 2016.

8. Deng QJ, Xie LQ and Li H: Overexpressed MALAT1 promotes invasion and metastasis of gastric cancer cells via increasing EGFL7 expression. Life Sci 157: 38-44, 2016

9. Ara H, Takagishi M, Enomoto A, Asai M, Ushida K, Asai N, Shimoyama Y, Kaibuchi K, Kodera Y and Takahashi M: Role for Daple in non-canonical Wnt signaling during gastric cancer invasion and metastasis. Cancer Sci 107: 133-139, 2016.

10. Armas P, Margarit E, Mouguelar VS, Allende ML and Calcaterra NB: Beyond the binding site: In vivo identification of tbx2, smarca5 and wnt5b as molecular targets of CNBP during embryonic development. PLoS One 8: e63234, 2013.

11. Miskolczi-McCallum CM, Scavetta RJ, Svendsen PC, Soanes KH and Brook WJ: The Drosophila melanogaster T-box genes midline and $\mathrm{H} 15$ are conserved regulators of heart development. Dev Biol 278: 459-472, 2005.

12. Takabatake Y, Takabatake T, Sasagawa S and Takeshima K: Conserved expression control and shared activity between cognate T-box genes TBX2 and Tbx 3 in connection with Sonic hedgehog signaling during Xenopus eye development. Dev Growth Differ 44: 257-271, 2002.

13. Takabatake Y, Takabatake T and Takeshima K: Conserved and divergent expression of T-box genes TBX2-Tbx 5 in Xenopus. Mech Dev 91: 433-437, 2000.

14. Papaioannou VE: The T-box gene family: Emerging roles in development, stem cells and cancer. Development 141: 3819-3833, 2014.

15. Takahashi H: Functional evolution of T-box gene family on animal development. Tanpakushitsu Kakusan Koso 46: 1349-1357, 2001 (In Japanese).

16. Papaioannou VE and Silver LM: The T-box gene family. Bioessays 20: 9-19, 1998.

17. Yi CH, Terrett JA, Li QY, Ellington K, Packham EA, Armstrong-Buisseret L, McClure P, Slingsby T and Brook JD: Identification, mapping and phylogenomic analysis of four new human members of the T-box gene family: EOMES, TBX6, TBX18 and TBX19. Genomics 55: 10-20, 1999.

18. Brend T and Holley SA: Expression of the oscillating gene herl is directly regulated by Hairy/Enhancer of Split, T-box and Suppressor of Hairless proteins in the zebrafish segmentation clock. Dev Dyn 238: 2745-2759, 2009.

19. Butz NV, Gronostajski RM and Campbell CE: T-box proteins differentially activate the expression of the endogenous interferon gamma gene versus transfected reporter genes in non-immune cells. Gene 377: 130-139, 2006.

20. Wan Z, Jiang D, Chen S, Jiao J, Ji L, Shah AS, Wei H, Yang X, Li X, Wang Y and Xiao J: T-box transcription factor brachyury promotes tumor cell invasion and metastasis in non-small cell lung cancer via upregulation of matrix metalloproteinase 12 Oncol Rep 36: 306-314, 2016.

21. Yu H, Liu BO, Liu A, Li K and Zhao H: T-box 2 expression predicts poor prognosis in gastric cancer. Oncol Lett 10: 1689-1693, 2015. 
22. Chen S, Jiao J, Jiang D, Wan Z, Li L, Li K, Xu L, Zhou Z, Xu W and Xiao J: T-box transcription factor Brachyury in lung cancer cells inhibits macrophage infiltration by suppressing CCL2 and CCL4 chemokines. Tumour Biol 36: 5881-5890, 2015.

23. Abrahams A, Parker MI and Prince S: The T-box transcription factor TBX2: Its role in development and possible implication in cancer. IUBMB Life 62: 92-102, 2010.

24. Douglas NC and Papaioannou VE: The T-box transcription factors TBX2 and TBX3 in mammary gland development and breast cancer. J Mammary Gland Biol Neoplasia 18: 143-147, 2013.

25. Boskovic $G$ and Niles RM: T-box binding protein type two (TBX2) is an immediate early gene target in retinoic-acid-treated B16 murine melanoma cells. Exp Cell Res 295: 281-289, 2004

26. Liu WK, Jiang XY and Zhang ZX: Expression of PSCA, PIWIL1 and TBX2 in endometrial adenocarcinoma. Onkologie 33: 241-245, 2010.

27. LiuWK,JiangXYandZhangZX:Expression ofPSCA,PIWIL1 and TBX2 and its correlation with HPV16 infection in formalin-fixed, paraffin-embedded cervical squamous cell carcinoma specimens. Arch Virol 157: 657-663, 2010.

28. Han Y, Tu WW, Wen YG, Yan DW, Qiu GQ, Peng ZH and Zhou CZ: Increased expression of TBX2 is a novel independent prognostic biomarker of a worse outcome in colorectal cancer patients after curative surgery and a potential therapeutic target. Med Oncol 30: 688, 2013.

29. Duo S, Tiao-Dong T, Lei Z, Wei W, Hong-Li S and Xian-Wei D: Expression and clinical significance of tbx2 in pancreatic cancer Asian Pac J Cancer Prev 10: 118-122, 2009.

30. Ludtke TH, Farin HF, Rudat C, Schuster-Gossler K, Petry M, Barnett P, Christoffels VM and Kispert A: TBX2 controls lung growth by direct repression of the cell cycle inhibitor genes Cdkn1a and Cdkn1b. PLoS Genet 9: e1003189, 2013.

31. Bilican B and Goding CR: Cell cycle regulation of the T-box transcription factor tbx2. Exp Cell Res 312: 2358-2366, 2006.

32. Figueira RC, Gomes LR, Neto JS, Silva FC, Silva ID and Sogayar MC: Correlation between MMPs and their inhibitors in breast cancer tumor tissue specimens and in cell lines with different metastatic potential. BMC Cancer 9: 20, 2009.

33. Nutt JE, Durkan GC, Mellon JK and Lunec J: Matrix metalloproteinases (MMPs) in bladder cancer: The induction of MMP9 by epidermal growth factor and its detection in urine. BJU Int 91: 99-104, 2003.

34. Bachmeier BE, Nerlich AG, Lichtinghagen $\mathrm{R}$ and Sommerhoff CP: Matrix metalloproteinases (MMPs) in breast cancer cell lines of different tumorigenicity. Anticancer Res 21: 3821-3828, 2001

35. Roh MR, Zheng Z, Kim HS, Kwon JE, Jeung HC, Rha SY and Chung KY: Differential expression patterns of MMPs and their role in the invasion of epithelial premalignant tumors and invasive cutaneous squamous cell carcinoma. Exp Mol Pathol 92. 236-242, 2012

36. Jung SA, Yang SK, Kim JS, Shim KN, Im SA, Myung SJ, Jung HY, Yu CS, Kim JC, Hong WS, et al: The expression of matrix metalloproteinases (MMPs), tissue inhibitor of metalloproteinases (TIMPs) and angiogenesis in relation to the depth of tumor invasion and lymph node metastasis in submucosally invasive colorectal carcinoma. Korean J Gastroenterol 45: 401-408, 2005 (In Korean)

37. Hotary KB, Yana I, Sabeh F, Li XY, Holmbeck K, Birkedal-Hansen H, Allen ED, Hiraoka N and Weiss SJ: Matrix metalloproteinases (MMPs) regulate fibrin-invasive activity via MT1-MMP-dependent and -independent processes. J Exp Med 195: 295-308, 2002.
38. Matos ML, Lapyckyj L, Rosso M, Besso MJ, Mencucci MV, Briggiler CI, Giustina S, Furlong LI and Vazquez-Levin MH: Identification of a Novel Human E-cadherin splice variant and assessment of its effects upon EMT-related events. J Cell Physiol 232: 1368-1386, 2016.

39. Rogers CD, Saxena A and Bronner ME: Sip1 mediates an E-cadherin-to-N-cadherin switch during cranial neural crest EMT. J Cell Biol 203: 835-847, 2013.

40. Prince S, Carreira S, Vance KW, Abrahams A and Goding CR: TBX2 directly represses the expression of the p21 (WAF1) cyclin-dependent kinase inhibitor. Cancer Res 64: 1669-1674, 2004.

41. Huang Y,LiZ,Zhong Q, Li G, Zhang Y and Huang Z: Association of TBX2 and P21 expression with clinicopathological features and survival of laryngeal squamous cell carcinoma. Int J Clin Exp Med 7: 5394-5402, 2014.

42. Zheng X, Wang Y, Liu B, Liu C, Liu D, Zhu J, Yang C, Yan J, Liao X, Meng X and Yang H: Bmi-1-shRNA inhibits the proliferation of lung adenocarcinoma cells by blocking the G1/S phase through decreasing cyclin D1 and increasing p21/p27 levels. Nucleic Acid Ther 24: 210-216, 2014.

43. Bartkova J, Lukas J, Strauss M and Bartek J: Cyclin D3: Requirement for G1/S transition and high abundance in quiescent tissues suggest a dual role in proliferation and differentiation. Oncogene 17: 1027-1037, 1998.

44. Chen JR, Chatterjee B, Meyer R, Yu JC, Borke JL, Isales CM, Kirby ML, Lo CW and Bollag RJ: TBX2 represses expression of Connexin43 in osteoblastic-like cells. Calcif Tissue Int 74: 561-573, 2004.

45. D'Costa ZC, Higgins C, Ong CW, Irwin GW, Boyle D, McArt DG, McCloskey K, Buckley NE, Crawford NT, Thiagarajan L, et al: TBX2 represses CST6 resulting in uncontrolled legumain activity to sustain breast cancer proliferation: A novel cancer-selective target pathway with therapeutic opportunities. Oncotarget 5: 1609-1620, 2014.

46. Nandana S, Tripathi M, Duan P, Chu CY, Mishra R, Liu C, Jin R, Yamashita H, Zayzafoon M, Bhowmick NA, et al: Bone metastasis of prostate cancer can be therapeutically targeted at the TBX2-WNT signaling axis. Cancer Res 77: 1331-1344, 2017.

47. Ma JW, Zhang Y, Ye JC, Li R, Wen YL, Huang JX and Zhong XY Tetrandrine exerts a radiosensitization effect on human glioma through inhibiting proliferation by attenuating ERK phosphorylation. Biomol Ther (Seoul) 25: 186-193, 2017.

48. Selvaraj P, Xiao L, Lee C, Murthy SR, Cawley NX, Lane M, Merchenthaler I, Ahn S and Loh YP: Neurotrophic Factor- $\alpha 1$ : A key wnt- $\beta$-catenin dependent anti-proliferation factor and ERK-Sox9 activated inducer of embryonic neural stem cell differentiation to astrocytes in neurodevelopment. Stem Cells 35: 557-571, 2017.

49. Liu X, Tian S, Liu M, Jian L and Zhao L: Wogonin inhibits the proliferation and invasion and induces the apoptosis of HepG2 and Bel7402 HCC cells through NFxB/Bcl-2, EGFR and EGFR downstream ERK/AKT signaling. Int J Mol Med 38: 1250-1256, 2016.

50. Hamaoka Y, Negishi M and Katoh H: EphA2 is a key effector of the MEK/ERK/RSK pathway regulating glioblastoma cell proliferation. Cell Signal 28: 937-945, 2016.

his work is licensed under a Creative Commons Attribution-NonCommercial-NoDerivatives 4.0 International (CC BY-NC-ND 4.0) License. 